\title{
Simple Resistor-less Generator Utilizing Z-copy Controlled Gain Voltage Differencing Current Conveyor for PWM Generation
}

\author{
Jan Jerabek ${ }^{1}$, Roman Sotner ${ }^{2}$, Tomas Dostal ${ }^{3}$, Kamil Vrba ${ }^{1}$ \\ ${ }^{I}$ Department of Telecommunications, Faculty of Electrical Engineering and Communication, \\ Brno University of Technology, \\ Technicka 12, Brno, 616 00, Czech Republic \\ ${ }^{2}$ Department of Radio Electronics, Faculty of Electrical Engineering and Communication, \\ Brno University of Technology, \\ Technicka 12, Brno, 616 00, Czech Republic \\ ${ }^{3}$ Department of Electrical Engineering and Computer Science, College of Polytechnics Jihlava, \\ Tolsteho 16, Jihlava 586 01, Czech Republic \\ sotner@feec.vutbr.cz.
}

\begin{abstract}
This paper deals with a very simple functional generator employing single multi-terminal advanced active device, so-called z-copy controlled gain voltage differencing current conveyor (ZC-CG-VDCC). This active element offers various inter-terminal relations and interesting possibilities of multi-parameter electronic control, which are utilized to control resulting application (triangular and square wave generator). Simple pulse width modulator (PWM) based on two ZC-CG-VDCCs is a further application example of presented generator. Verification of expected behavior was performed by simulation based on CMOS model of the ZC-CG-VDCC and also by lab measurement.
\end{abstract}

Index Terms-Electronic control, functional generator, multiple-terminal advanced active element, PWM, voltage differencing current conveyor, ZC-CG-VDCC.

\section{INTRODUCTION}

Advanced or special active elements [1] are useful in circuit synthesis and design from many substantial reasons. First of all, they dispose of various interesting terminal relations [1] useful for simplification of circuit synthesis of standard, advanced or special applications. The next beneficial feature of advanced active elements consists in direct independent electronic control of several parameters included in frame of active device, for example [2]-[5]. Common active elements for circuit design (operational amplifiers for example) realize only one and very simple signal operation $\left(V_{\text {out }}=\left(V_{+}-V_{-}\right) \cdot A\right.$, where $\left.A \rightarrow \infty\right)$ [6], [7] without possibility of electronic control of its parameter(s) in

Manuscript received March 9, 2015; accepted June 29, 2015. Research described in this paper was financed by Czech Ministry of Education in frame of National Sustainability Program under grant LO1401. For research, infrastructure of the SIX Center was used. Research described in the paper was supported by Czech Science Foundation projects under No. 14-24186P. Grant No. FEKT-S-14-2281 also supported this research. The support of the project CZ.1.07/2.3.00/20.0007 WICOMT, financed from the operational program Education for competitiveness, is gratefully acknowledged. many cases. Beneficial features of advanced active elements can be also used in the design of functional generators.

Electronically controllable functional (triangular and square wave) generators are widely employed in many analog and digital communication subsystems (clock generation, pulse width modulation, TTL or CMOS logic, DC-DC, AC-DC converters, etc.) [6], [7].

Operational transconductance amplifiers (OTA) [1], [8] were the first active elements that were very suitable for design of generators.

\section{DisCUSSION OF RELATED RESEARCH}

Siripruchyanun et al. [9] and Chung et al. [10] proposed a generator based on three adjustable OTAs and three passive elements. Three commercially available active elements were utilized in solution presented in [11], where electronic controllability of the solution was the main contribution.

Another solution employing two (indivisible to subblocks) active elements and four passive elements was reported by Janecek et al. [12]. However, his work does not focuses on electronic controllability. Chien [13] proposed a generator based on two differential voltage current conveyors (DVCCs) that are multi-terminal active elements, and four passive elements.

Kumbun et al. [14] starts with utilization of electronically controllable active elements with active subsections. Their active element, referred to as multiple-output through transconductance amplifiers (MO-CTTA) employs current amplifier with special input feature (sCA) and OTA. Two MO-CTTA are required for construction of the generator. The same number of active devices is required for generators presented by Silapan et al. [15]. Silapan et al. [15] used two multiple-output current controlled current differencing amplifiers (MO-CCCDTAs) which consist of current differencing unit (CDU) [1], [16], [17] and OTA subsections. A solution presented by Srisakul [18] is based 
on multiple-output current controlled current conveyor transconductance amplifier (MO-CCCCTA) where current controlled current conveyor of second generation (CCCII) [1], [19], [20] and OTA create subsections.

Two active elements are sufficient for construction of a functional generator presented in [21], where dual-output voltage differencing buffered amplifier (DO-VDBA) and fully balanced voltage differencing amplifier (FB-VDBA) were employed. These elements are created by internal subsections in a form of operational transconductance amplifier and voltage buffer (VB) or voltage inverter (VI). The proposed generator allows differential outputs of both generated responses.

Single active element, so-called controlled gain current and differential voltage amplifier (CG-CDVA) is sufficient for construction of the generator presented in [22]. Active devices consist of adjustable current amplifier (aCA) and adjustable differential voltage amplifier (DVCA) subsections.

Therefore, a solution of generator, introduced in this paper, offers some significant improvements. Employed active element is not complex and only one element is enough in order to form the generator. Number of external passive elements is decreased to only one grounded capacitor and both signals (square and triangle wave) are available in both voltage and current form. Moreover, functions of our solution are experimentally verified in order to prove the correctness of our concept.

\section{ACTIVE ELEMENT DESCRIPTION}

Z-copy Controlled Gain Voltage Differencing Current Conveyor (ZC-CG-VDCC) is an active device covering high variability of terminal relations and controllable parameters itself that is highly beneficial for many applications. A detailed principle is discussed in [4] and [5], where we can find also internal CMOS structure that was used for simulations also in this paper. Therefore, we provide only brief explanation of ideal behavior of this multi-terminal active element. Simplified behavioral block model is shown in Fig. 1. In fact, ZC-CG-VDCC is interconnection of two main sub-blocks: OTA and electronically controllable current conveyor of second generation (ECCII) [1]-[3].

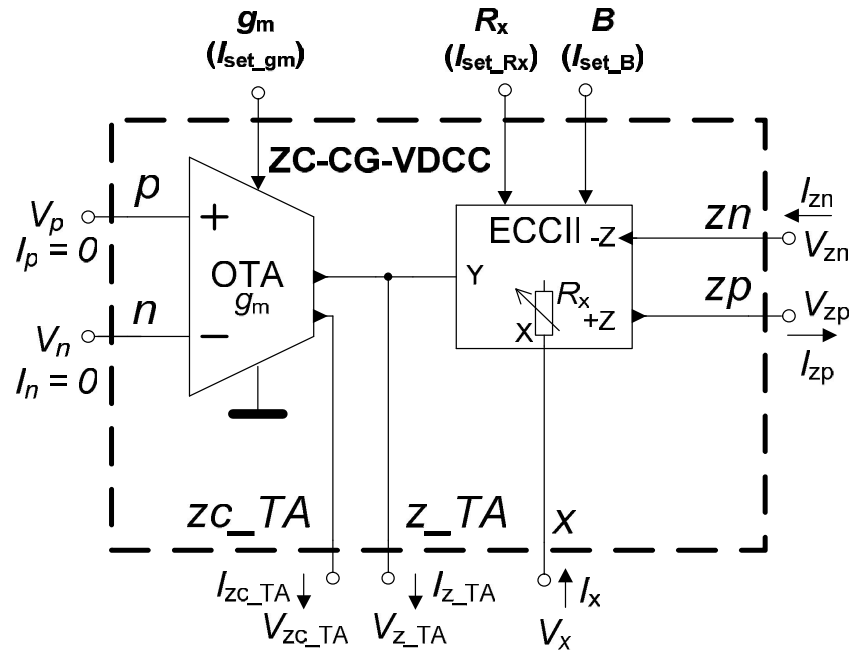

Fig. 1. Behavioral sub-block model of the ZC-CG-VDCC.
Behavior of model in Fig. 1 is defined by:

$$
\begin{gathered}
I_{z_{-} T A}=I_{z c_{-} T A}=\left(V_{p}-V_{n}\right) g_{m}, \\
V_{x}=V_{z_{-} T A}+R_{x} I_{x}, \\
I_{z p}=-I_{z n}=B \times I_{x},
\end{gathered}
$$

where controllable parameters are transconductance $\left(g_{\mathrm{m}}\right)$

$$
g_{m}=2 \sqrt{I_{\text {set_gm }} K_{P n} \frac{W_{M 1,2}}{L_{M 1,2}}},
$$

internal resistance of current input terminal $\mathrm{X}\left(R_{\mathrm{X}}\right)$

$$
R_{x}=\frac{1}{\sqrt{I_{\text {set_Rx }} K_{P n} \frac{W_{M 11,12}}{L_{M 11,12}}}+\sqrt{I_{\text {set_Rx }} K_{P p} \frac{W_{M 13,14}}{L_{M 13,14}}}}
$$

and current gain $B$

$$
B=\frac{N I_{b 2}}{2 I_{\text {set_ } B} B} \cong \frac{I_{b 2}}{I_{\text {set_ } B} B} .
$$

Parameters $I_{\text {set_gm }}, I_{\text {set_Rx}}, I_{\text {set_B }}, I_{\mathrm{b} 2}$ are values of internal bias sources of the CMOS structure, $W_{\mathrm{M}}$ and $L_{\mathrm{M}}$ are dimensions of used transistors and $K_{\mathrm{P}}$ are transconductance parameters for used fabrication technology (for more details see [5]).

\section{FunCTIONAL GENERATOR}

The proposed generator in Fig. 2 is formed by two parts: integrator and comparator (Schmitt trigger). We can form these subparts very simply by internal sections of the $\mathrm{ZC}$ CG-VDCC (integrator = capacitor + OTA section, comparator $=$ ECCII section). Square wave is available also in form of current flowing from $z c_{-} T A$ terminal.

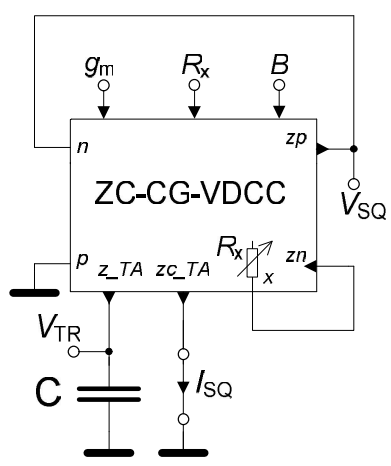

Fig. 2. Triangle and square wave generator based on ZC-CG-VDCC

A part of the comparator (input $z_{-} T A$, output $z p$ ) has the following principle. The highest current gain in structure of ZC-CG-VDCC has theoretical maximum limited to $B_{\max } \approx 4$ [4], [5] for very low DC bias current $I_{\text {set_B. Voltage transfer }}$ between $z_{-} T A$ and $z n$ terminals has ideal formula

$$
\frac{V_{z n}}{V_{z_{-} T A}}=\frac{1-B}{1-B},
$$


where transfer has character of unity gain voltage amplifier for $B<1$. In case of $B \geq 1$, this part of active element behaves as comparator with hysteresis [10]. Direct copy of current $I_{\mathrm{X}}$ (in saturation given by $I_{\mathrm{b} 1}=100 \mu \mathrm{A}$ in [5]) multiplied by gain $B$ is available at terminal $z p$. Voltage at this terminal is in saturation corner without load resistance. Between $z n$ and $z_{-} T A$ terminals unity gain (7) still persists, therefore threshold input voltages are equal to saturation corners $\pm V_{\text {zn/zn_sat }}$ (approximately $\pm 0.8 \mathrm{~V}$ to $\pm 0.9 \mathrm{~V}$ in our case). Due to this fact, we can obtain equal amplitudes of triangular and square wave response. This statement is valid only for $B \geq 1$ in real case.

Supposing equality of threshold and output level of the repeating frequency is given (for $50 \%$ duty cycle) as

$$
f_{0}=\frac{I_{s e t_{-} g m}}{2 V_{T R_{-} \max } C},
$$

where $V_{\text {TR_max }}=V_{\text {SQ_max }}$ and 2 in denominator comes from current mirror ratio in CMOS structure [5]. The proposed variant of the generator can also operate with different duty cycle $(D)$ than $50 \%$, see Fig. 3. Only one additional DC current source is supplemented into the structure.

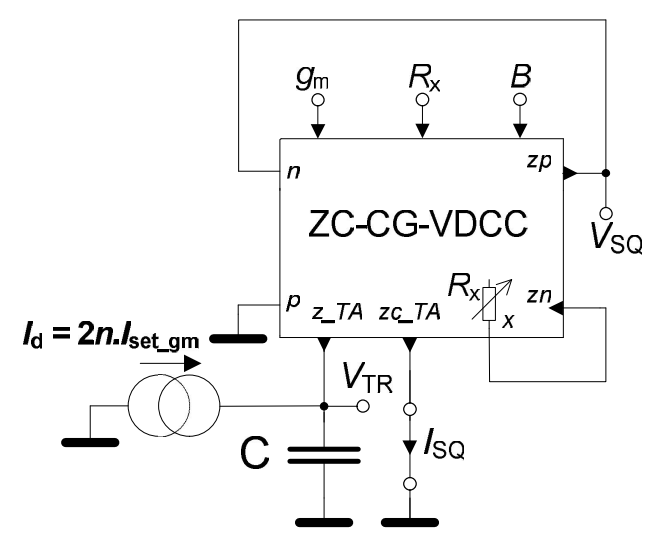

Fig. 3. Triangle and square wave generator with duty cycle control based on ZC-CG-VDCC.

Using routine analysis, we obtain the following expression for repeating frequency

$$
\begin{gathered}
f_{0}=\frac{I_{z_{-} T A_{-} \max }\left(1-\frac{I_{d}}{I_{z_{-} T A_{-} \max }}\right)\left(1+\frac{I_{d}}{I_{z_{-} T A_{-} \max }}\right)}{4 V_{T R_{-} \max } C}= \\
=\frac{I_{s e t_{-} g m}\left(1-\frac{I_{d}}{2 I_{s e t_{-} g m}}\right)\left(1+\frac{I_{d}}{2 I_{s e t_{-} g m}}\right)}{2 V_{T R_{-} \max } C},
\end{gathered}
$$

and duty cycle $\left(I_{z_{-} \text {TA_max }}=2 I_{\text {set_gm }}\right)$

$$
D=\frac{1}{2}\left(1+\frac{I_{d}}{2 I_{\text {set_gm }}}\right)=\frac{1}{2}(1+n),
$$

where $n=I_{\mathrm{d}} / 2 I_{\text {set_gm }}$ and represents relation between $D$ and $f_{0}$. ( $I_{\mathrm{d}}$ is theoretically limited to $\left.\pm 2 I_{\text {set_gm }}\right)$. Constant 2 is also given by multiplication of current mirrors in OTA section in frame of the ZC-CG-VDCC element (see [5]). Setting of $D$ independently of $f_{0}$ is also possible for constant ratio $n=2 D-1 \quad\left(I_{\mathrm{d}}=2 . I_{\mathrm{set} \_g m}(2 D-1)\right)$. Accurate ratio of two DC currents is quite easily available in IC design.

\section{Simulation Results}

\section{A. Functional Generator}

We obtained the following simulation results for parameters: $C=40 \mathrm{pF}, R_{\mathrm{x}}=1 \mathrm{k} \Omega\left(I_{\text {set_Rx }}=34 \mu \mathrm{A}\right), g_{\mathrm{m}}=$ $1 \mathrm{mS}\left(I_{\text {set_gm }}=54 \mu \mathrm{A}\right), B=2\left(I_{\text {set_B }}=58 \mu \mathrm{A}\right)$. Transient responses $\left(V_{\mathrm{TR}}, V_{\mathrm{SQ}}\right)$ are given in Fig. 4 for theoretical $f_{0}=0.844 \mathrm{MHz}$. The repeating frequency obtained from simulation was $0.904 \mathrm{MHz}$. The triangle wave signal has inverting polarity (consequence of inverting Schmitt trigger). Tuning of the generator (Fig. 5) was verified from $109 \mathrm{kHz}$ to $1479 \mathrm{kHz}$ by adjusting of $I_{\text {set_gm }}$ from $5 \mu \mathrm{A}$ to $99 \mu \mathrm{A}$ (ideal range of $f_{0}$ control is $78 \mathrm{kHz}-1547 \mathrm{kHz}$ ). Range of the adjusting is proportional to $I_{\text {set_gm. }}$.

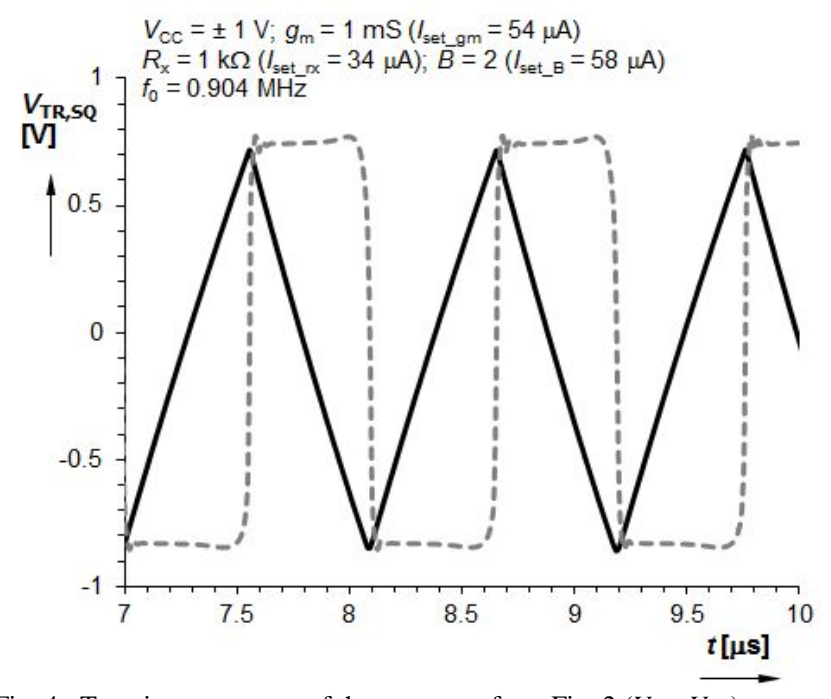

Fig. 4. Transient responses of the generator from Fig. $2\left(V_{\mathrm{TR}}, V_{\mathrm{SQ}}\right)$.

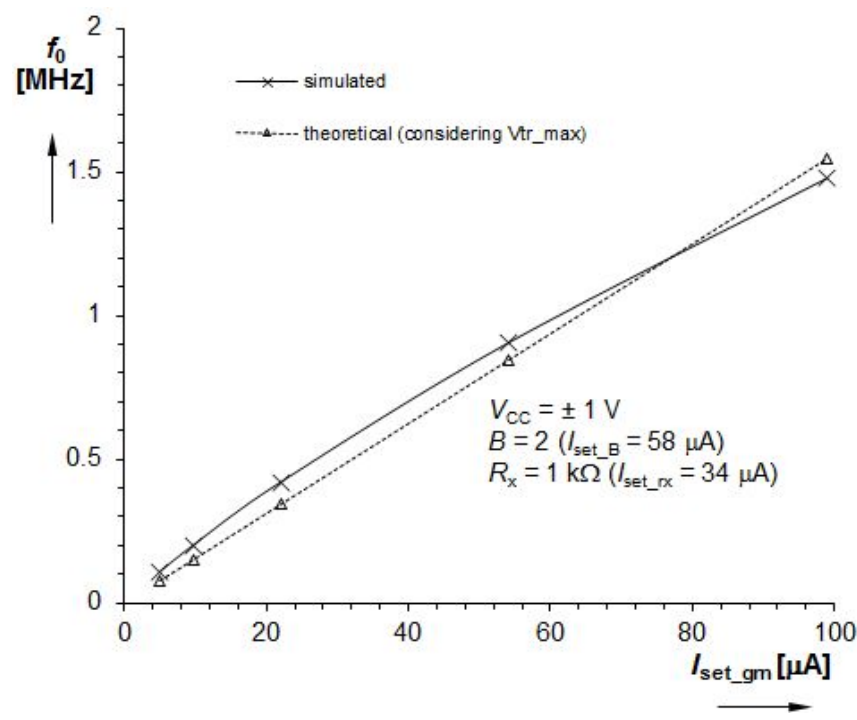

Fig. 5. Dependence of the repeating frequency on DC bias current $I_{\text {set_gm. }}$.

The results of exemplary $f_{0}$ tuning for two different frequencies and $D=30 \%$ or $70 \%$ (simulated as $29.7 \%$ and $30.8 \%$ or $66.9 \%$ and $69.7 \%$ ) are given in Fig. 6 and Fig. 7. Utilization of current output terminal $z c_{-} T A$ (resistive load at 
this terminal) allows to obtain differential voltage output of the square wave that is useful in low-voltage and low power applications, where voltage swing is very limited.

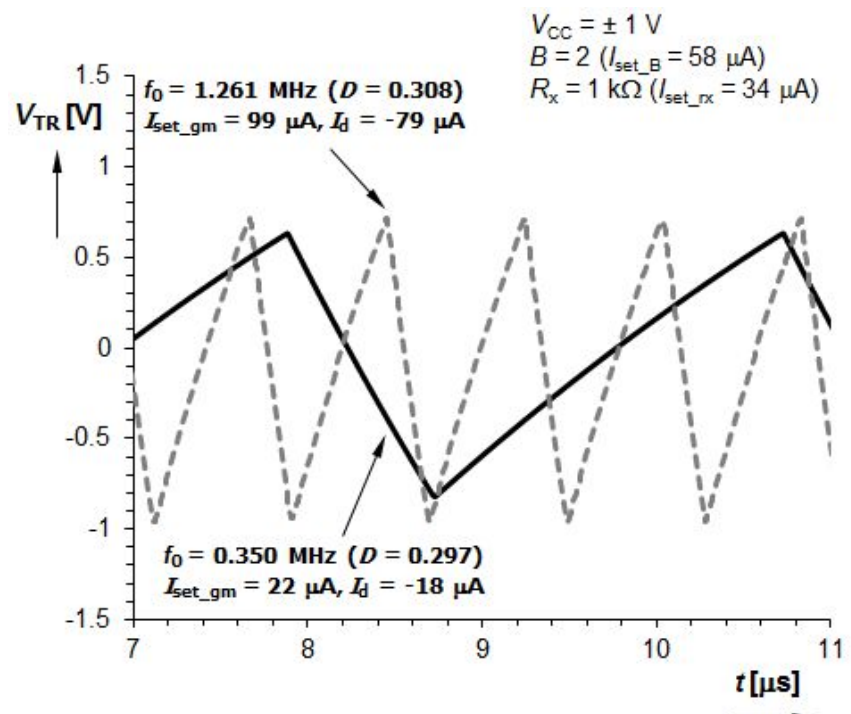

a)

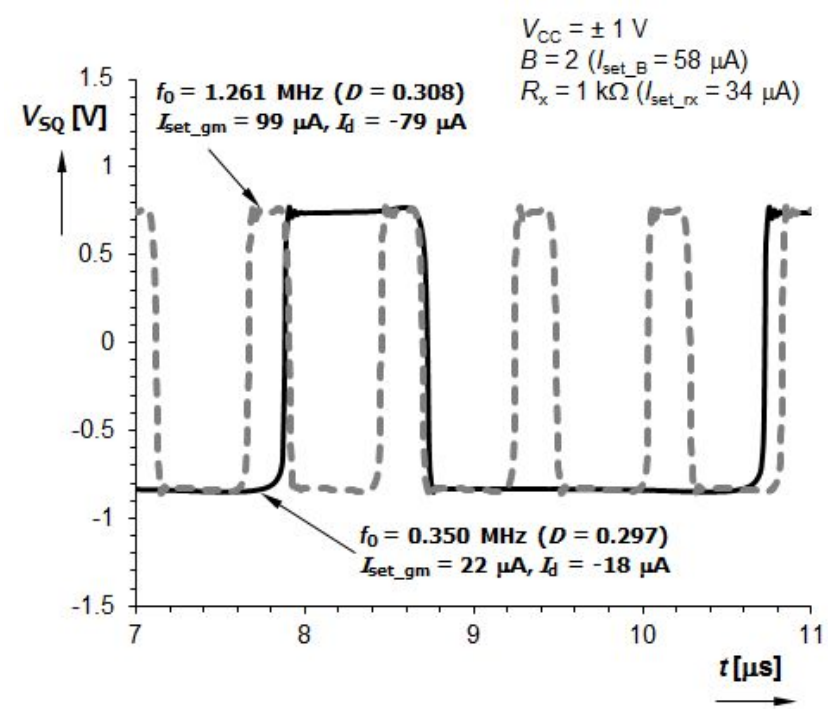

b)

Fig. 6. Transient response for $f_{0}$ adjusting with $D=30 \%$ : a) triangle wave, b) square wave.

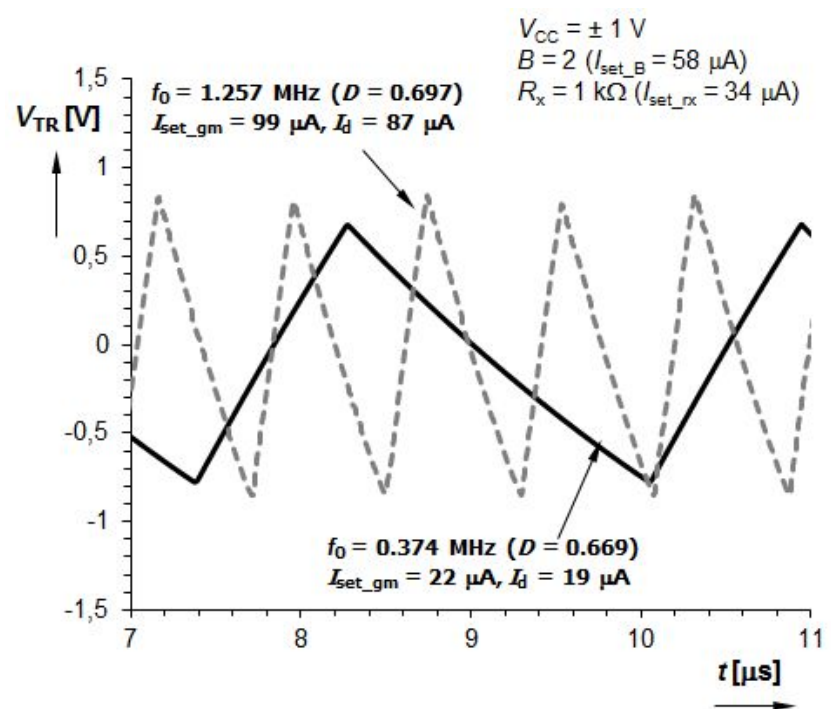

a)

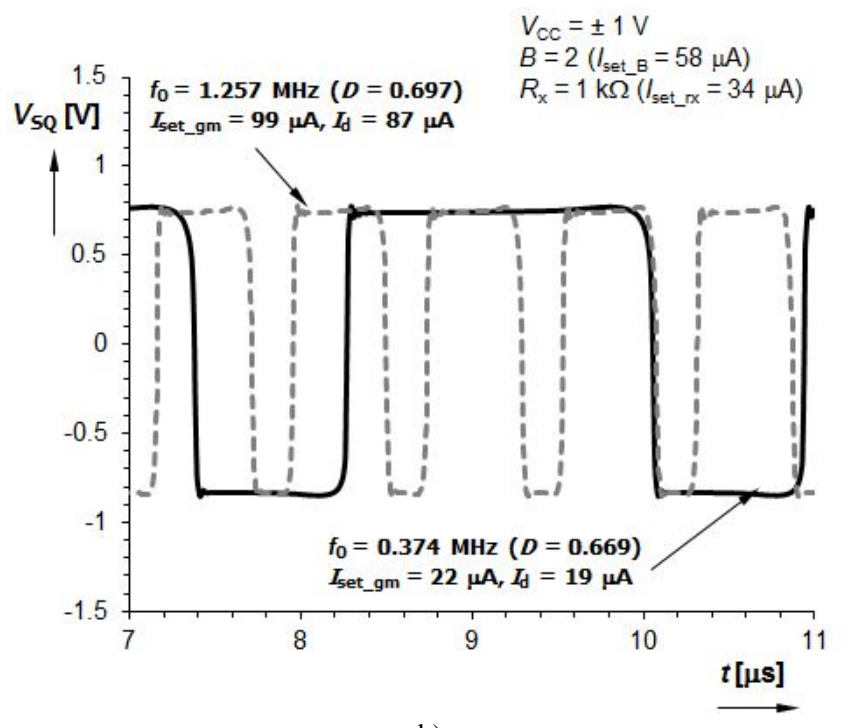

b)

Fig. 7. Transient response for $f_{0}$ adjusting with $D=70 \%$ : a) triangle wave, b) square wave.

\section{B. PWM Modulator}

Pulse width modulator (PWM) [23] is both quite important and typical application of the functional generator. PWM modulators are frequently used in power supply sources/converters (DC-DC, AC-DC) and high-efficient audio amplifiers (D class) for example. We established the following PWM modulator (Fig. 8) as a simple example of utilization of the triangular wave output of the generator. Two ZC-CG-VDCCs are sufficient to provide simple PWM modulator employing low number of passive elements (one $R$ and one $C$ only). Input OTA section of the ZC-CG$\mathrm{VDCC}_{2}$ which is directly connected to the current conveyor CCII input $Y\left(z_{-} T A\right)$ forms simple comparator without hysteresis. Output response is available after internal voltage buffer in frame of CCII part (at X terminal).

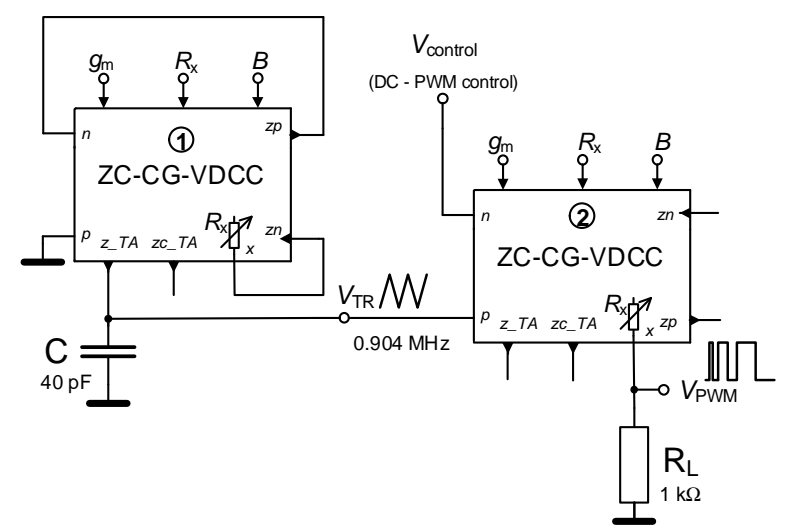

Fig. 8. A simple pulse width modulator based on two ZC-CG-VDCC.

Output of the PWM is terminated by load resistance $1 \mathrm{k} \Omega$ and rest of terminals (ZC-CG-VDCCs) was kept unconnected or grounded. Configuration of the modulator was set as: repeating frequency $0.904 \mathrm{MHz}, C=40 \mathrm{pF}$. Additional parameters (bias currents) are noted in figures including simulation results (Fig. 9). We tested system in two situations: a) linear sweep of DC control voltage $\left(V_{\text {control }}\right)$ from $-0.8 \mathrm{~V}$ to $0.8 \mathrm{~V}$ and $\mathrm{b}$ ) harmonic excitation $\left(1.1 V_{\mathrm{p}-\mathrm{p}}, 50 \mathrm{kHz}\right)$. 

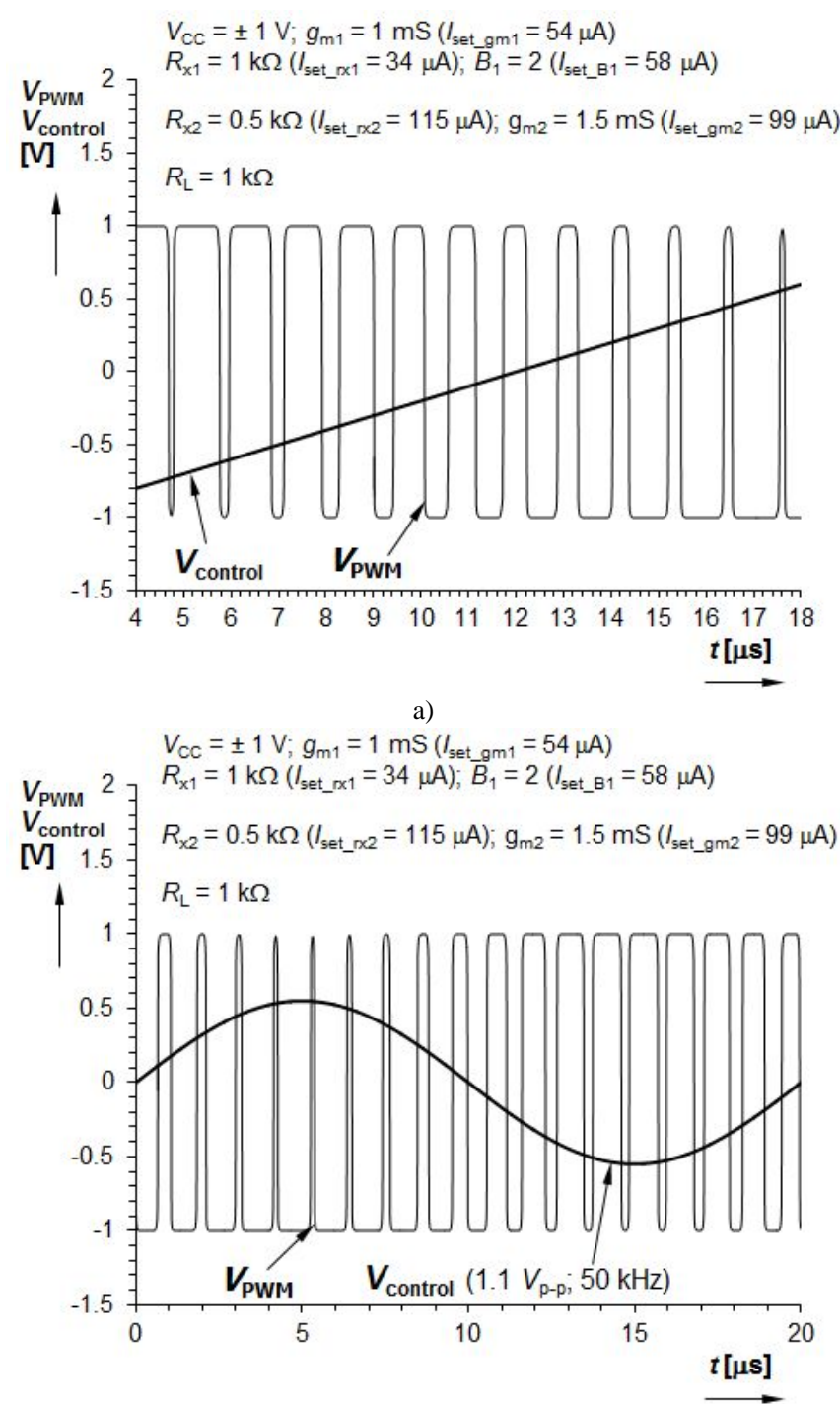

b)

Fig. 9. Results of the PWM modulator simulation: a) example of linear sweep, b) example of harmonic excitation.

\section{MEASUREMENT RESULtS}

Triangle and square wave generator based on ZC-CGVDCC (Fig. 2) was implemented to be measured in lab. Behavioral model of ZC-CG-VDCC consisting of commercially available active devices was prepared for such a reason. Prepared behavioral model is depicted in Fig. 10. The subpart consisting of ECCII- 1, ECCII-2, $\mathrm{VB}_{1}, \mathrm{VB}_{2}$ and $\mathrm{CF} / \mathrm{I}_{1}(\mathrm{CF} / \mathrm{I}$ - current follower and inverter) emulates overall ECCII section in Fig. 1. The rest of blocks $\left(\mathrm{VCA}_{1}, \mathrm{ECCII}_{3}\right.$, $\mathrm{CF} / \mathrm{I}_{2}$ ) represents OTA section in Fig. 1. Three adjustable parameters [11], [24] of the basic model in Fig. 1 are defined as: $R_{\mathrm{X}} \cong R_{\mathrm{j}} / V_{\text {SET_Rx }}, B \cong V_{\text {SET_B }}$ and $g_{\mathrm{m}} \cong V_{\text {SET_gm }} / R_{\mathrm{k}}{ }_{\mathrm{K}}$. Our model includes also additional parameter $A$ (voltage gain) that is suitable for further development of applications (additional degree of freedom) that is available in relation between $I_{\mathrm{Z}_{-} \mathrm{TA}}\left(I_{\mathrm{Zc}_{-} \mathrm{TA}}\right.$ and $V_{\mathrm{p}}$ and $\left.V_{\mathrm{n}}\right)$ as: $\left(V_{\mathrm{p}}-V_{\mathrm{n}} A\right) g_{\mathrm{m}}=I_{\mathrm{Z}_{-} \mathrm{TA}}=$

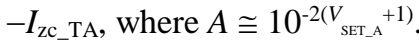

We used discussed behavioral model for verification of proposed generator in Fig. 2. Supposing equality of amplitudes of generated waveforms $\left(V_{\mathrm{SQ}_{\_} \max }=V_{\mathrm{TR}_{-} \max }\right)$, approximate equation for $f_{0}$ has it this case form

$$
f_{0_{-} m} \cong \frac{V_{S E T_{-} g m}}{4 R_{k}^{\prime} C} .
$$

The equation (11) is different than previous derivations because model in Fig. 10 only emulates behavior of the ZCCG-VDCC device and it has not exactly the same principle of operation as CMOS model of ZC-CG-VDCC in [5].

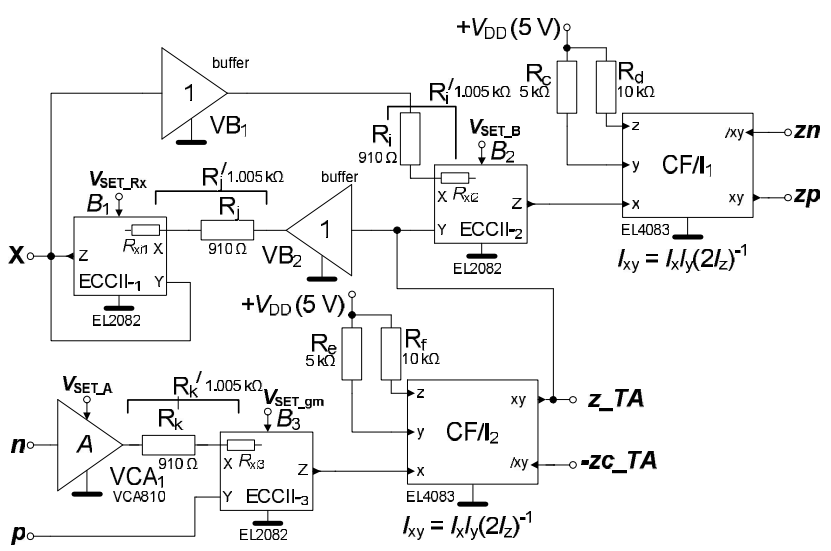

Fig. 10. Behavioral model of ZC-CF-VDCC (concept from Fig. 1) consisting of commercially available active devices.

As an example, transient responses of triangle and square wave signals with $D=50 \%$, and $f_{0}=11.1 \mathrm{kHz}$ $\left(V_{\text {SET_gm }}=0.04 \mathrm{~V}\right), f_{0}=110 \mathrm{kHz}\left(V_{\text {SET_gm }_{2}}=0.63 \mathrm{~V}\right)$ were selected (Fig. 11) were obtained for $C=1 \mathrm{nF}$. Values of other parameters and constants during tests are noted in the following Fig. 12. Dependence of $f_{0}$ on $V_{\mathrm{SET}_{-} g \mathrm{gm}}$ and dependence of output levels (peak-to-peak) on $f_{0}$ are shown in Fig. 12. Validity of approximate equation (11) was verified by measurement (Fig. 12) up to $80 \mathrm{kHz}$ $\left(V_{\text {SET_gm }_{2}}=0.32 \mathrm{~V}\right)$. As obvious from the graph, further increasing of $V_{\text {SET_gm }}$ causes problems with linearity of transfer characteristics and problems with slew-rate. Proposed behavioral model is obviously not suitable for high frequency operation with large signal levels (it reaches supply saturation corners in our case - see square waves in the graph), due to existence of high impedance node with large parasitic capacitance (frequency dependent impedance) of node of $V_{\mathrm{SQ}}$, where terminals $n$ and $z p$ are interconnected.

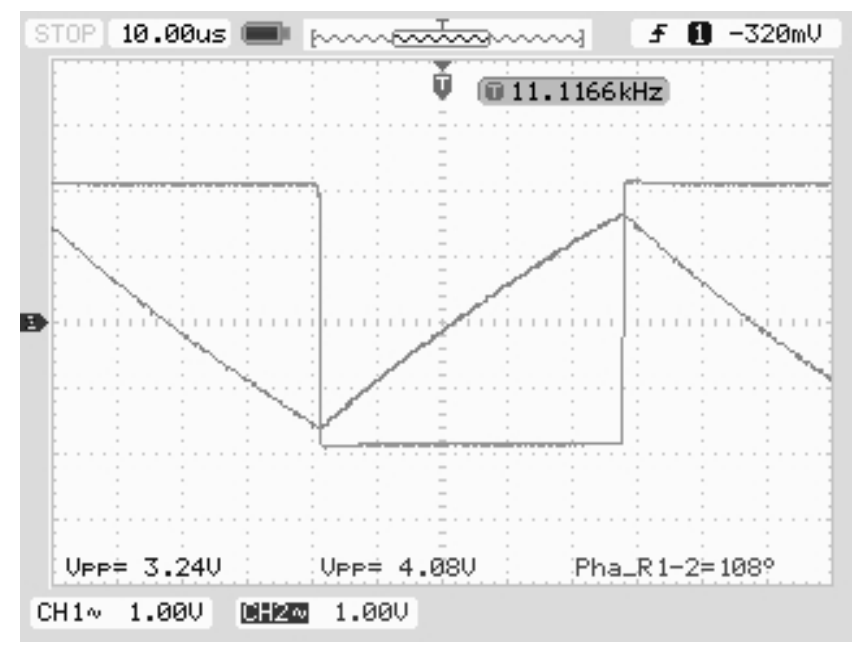

a) 


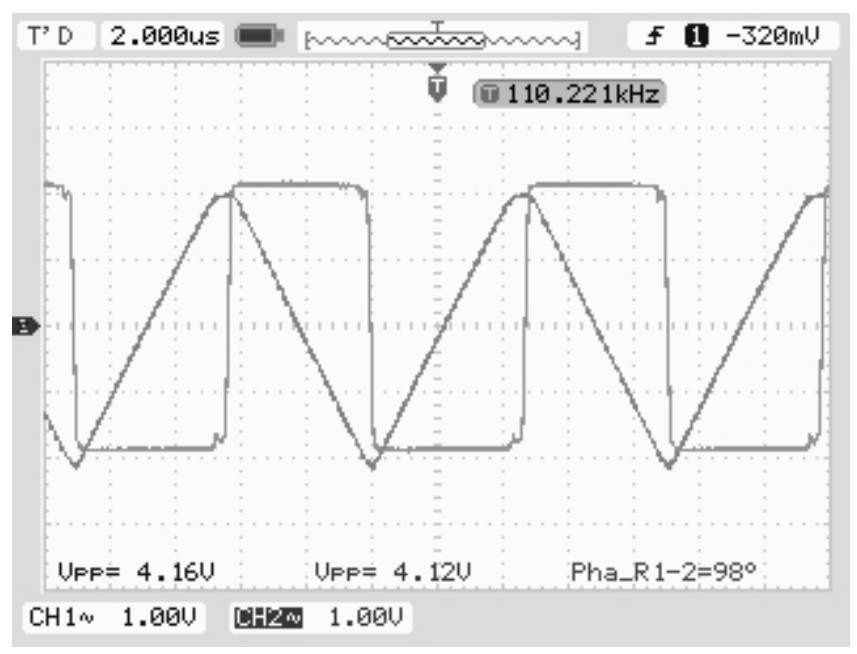

b)

Fig. 11. Measured transient responses for $f_{0}$ adjusting with $D=50 \%$ of the generator from Fig. 2 based on behavioral model in Fig. 10: a) $\left.f_{0}=11 \mathrm{kHz}, \mathrm{b}\right) f_{0}=110 \mathrm{kHz}$.

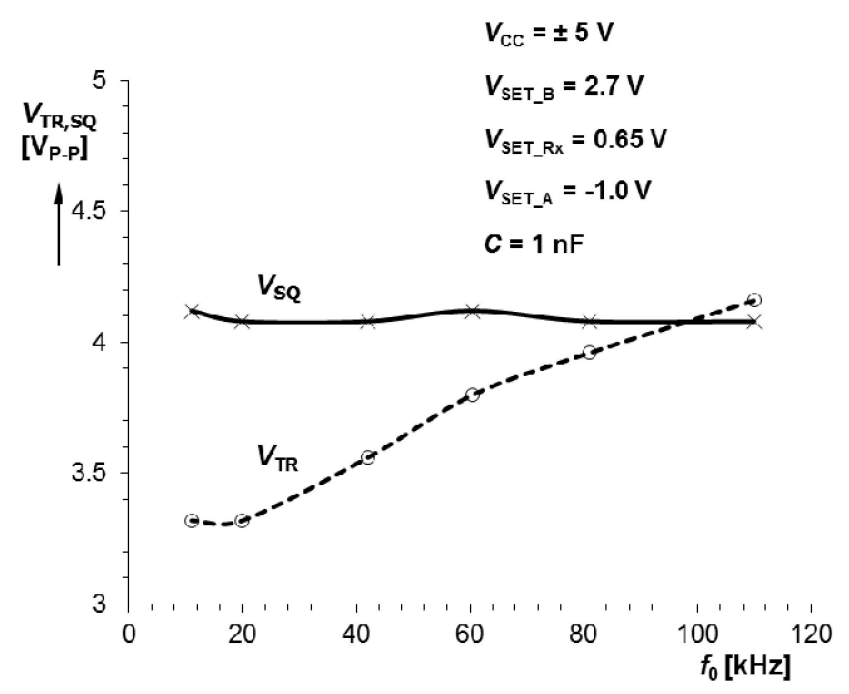

a)

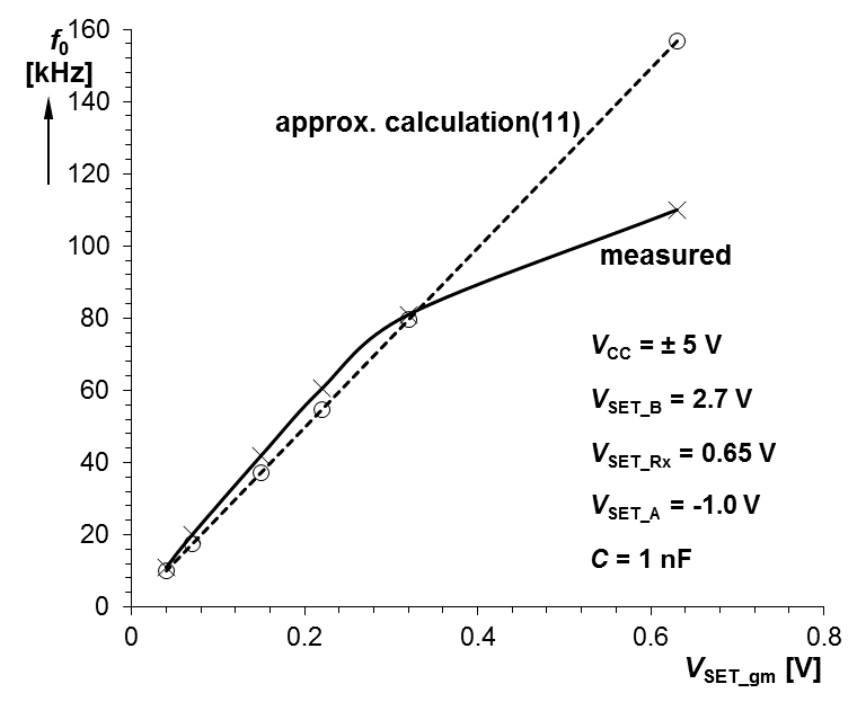

b)

Fig. 12. Measured dependences of: a) output levels on $f_{0}$, b) $f_{0}$ on $V_{\text {SET_gm. }}$

\section{CONCLUSIONS}

Presented functional generator requires only one active element and really low number of external passive elements (one capacitor only) and moreover it provides outputs (square and triangle wave) in both voltage and current form. By utilizing CMOS model of the active device from [5] we obtained very large adjustability range from $109 \mathrm{kHz}$ to $1479 \mathrm{kHz}$ by adjusting of $I_{\text {set_gm }}$ from $5 \mu \mathrm{A}$ to $99 \mu \mathrm{A}$. For comparison with already published solutions see Table I, where a brief overview was provided. Note that our work includes also real measurement results that prove the design correctness. Behavioral model suffers from the significant parasitics that limit useful bandwidth in this case, as was discussed in previous section, therefore it was measured in $11 \mathrm{kHz}$ to $110 \mathrm{kHz}$ range. Proposed generator can be used for PWM modulation by a very simple way - a part of additional active device is used for comparisons of triangular wave with constant DC component to create PWM signal. All adjustable parameters $\left(g_{\mathrm{m}}, R_{\mathrm{X}}, B\right)$ of the ZC-CG-VDCC were not necessary in the presented applications. Engagement of all controllable features is fully utilized in reconnection-less reconfigurable active filters [5] or multiphase oscillators [4] for example. Note that the generator can be obtained also if internal subsections (Fig. 1) of the ZC-CG-VDCC are interchanged (integrator is created by ECCII and comparator by OTA section) [25]. However, solution presented here saves two resistors.

TABLE I. COMPARISON OF SELECTED GENERATOR SOLUTIONS.

\begin{tabular}{|c|c|c|c|c|c|c|}
\hline 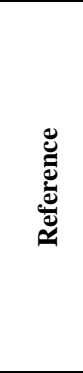 & 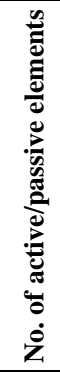 & 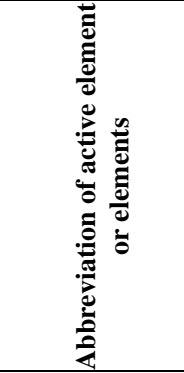 & 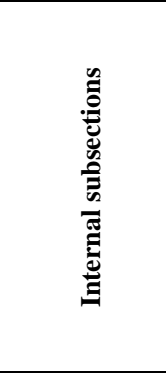 & 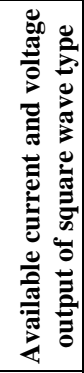 & 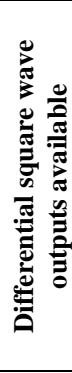 & 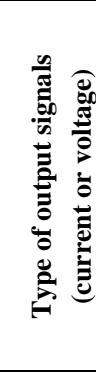 \\
\hline $\begin{array}{l}{[9],} \\
{[10]}\end{array}$ & $3 / 3$ & OTA & - & No & No & Voltage \\
\hline [11] & $3 / 2$ & $\begin{array}{c}2 \mathrm{x} V \mathrm{VA}+\mathrm{DT} \\
+\mathrm{VB}\end{array}$ & - & No & No & Voltage \\
\hline$[12]$ & $2 / 4$ & $\begin{array}{c}\mathrm{CCII}+\mathrm{UCC}+ \\
4 \text { diodes }\end{array}$ & - & N/A & Yes & Voltage \\
\hline$[13]$ & $2 / 4$ & DVCC & - & No & N/A & Voltage \\
\hline$[14]$ & $2 / 1$ & MO-CTTA & sCA+OTA & N/A & N/A & Current \\
\hline$[15]$ & $2 / 1$ & MO-CCCDTA & CDU+OTA & N/A & N/A & Current \\
\hline$[18]$ & $2 / 1$ & MO-CCССТА & CCCII+OTA & N/A & N/A & Current \\
\hline$[21]$ & $2 / 3$ & $\begin{array}{l}\text { DO-VDBA, } \\
\text { FB-VDBA }\end{array}$ & $\begin{array}{c}\mathrm{OTA}+\mathrm{VB}+\mathrm{V} \\
\mathrm{I} \\
\end{array}$ & Yes & Yes & Both \\
\hline [22] & $1 / 2$ & CG-CDVA & aCA+DVCA & No & No & Voltage \\
\hline [25] & $1 / 3$ & $\begin{array}{l}\text { ZC-CG- } \\
\text { VDCC }\end{array}$ & OTA+ECCII & Yes & Yes & Both \\
\hline Fig. 2 & $1 / 1$ & $\begin{array}{l}\text { ZC-CG- } \\
\text { VDCC }\end{array}$ & OTA+ECCII & Yes & Yes & Both \\
\hline
\end{tabular}

\section{REFERENCES}

[1] D. Biolek, R. Senani, V. Biolkova, Z. Kolka, "Active elements for analog signal processing: classification, review and new proposals", Radioengineering, vol. 17, no. 4, pp. 15-32, 2008.

[2] S. Minaei, O. K. Sayin, H. Kuntman, "A new CMOS electronically tunable current conveyor and its application to current-mode filters", IEEE Trans. on Circuits and Systems - I, vol. 53, no. 7, pp. 14481457, 2006. [Online]. Available: http://dx.doi.org/10.1109/TCSI.2006.875184 
[3] A. Marcellis, G. Ferri, N. C. Guerrini, G. Scotti, V. Stornelli, A. Trifiletti, "The VGC-CCII: a novel building block and its application to capacitance multiplication", Analog Integrated Circuits and Signal Processing, vol. 58, no. 1, pp. 55-59, 2009. [Online]. Available: http://dx.doi.org/10.1007/s10470-008-9213-6

[4] R. Sotner, J. Jerabek, J. Petrzela, N. Herencsar, R. Prokop, K. Vrba, "Second-order simple multiphase oscillator using Z-copy controlledgain voltage differencing current conveyor", Elektronika Ir Elektrotechnika, vol. 20, no. 9, pp. 13-18, 2014. [Online]. Available: http://dx.doi.org/10.5755/j01.eee.20.9.8709

[5] R. Sotner, N. Herencsar, J. Jerabek, R. Prokop, A. Kartci, T. Dostal, $\mathrm{K}$. Vrba, "Z-copy controlled-gain voltage differencing current conveyor: advanced possibilities in direct electronic control of firstorder filter", Elektronika Ir Elektrotechnika, vol. 20, no. 6, pp. 7783, 2014. [Online]. Available: http://dx.doi.org/10.5755/j01. eee.20.6.7272

[6] A. Basak, Analogue electronic circuits and systems. Cambridge University Press: New York, USA, 1991, p. 376. [Online]. Available: http://dx.doi.org/10.1017/CBO9781139168069

[7] P. R. Gray, P. J. Hurst, S. H. Lewis, R. G. Meyer, Analysis and design of analog integrated circuits. John Wiley and Sons, Inc.: USA, 2009, p. 896.

[8] R. L. Geiger, E. Sanchez-Sinencio, "Active filter design using operational transconductance amplifiers: a tutorial", IEEE Circ. and Devices Magazine, vol. 1, pp. 20-32, 1985. [Online]. Available: http://dx.doi.org/10.1109/MCD.1985.6311946

[9] M. Siripruchyanun, P. Wardkein, "A full independently adjustable, integrable simple current controlled oscillator and derivative PWM signal generator", IEICE Trans. Fundam. Electron. Commun. Comput. Sci., vol. E86-A, no. 12, pp. 3119-3126, 2003.

[10] W. S. Chung, H. Kim, H. W. Cha, H.J. Kim, "Triangular/square-wave generator with independently controllable frequency and amplitude", IEEE Trans. Instrumentation and Measurement, vol. 54, no. 1, pp. 105-109, 2005. [Online]. Available: http://dx.doi.org/10.1109/ TIM.2004.840238

[11] R. Sotner, J. Jerabek, N. Herencsar, A. Lahiri, J. Petrzela, K. Vrba, "Practical aspects of operation of simple triangular and square wave generator employing diamond transistor and controllable amplifiers", in Proc. 36th Int. Conf. Telecommunications and Signal Processing (TSP 2013), Rome, 2013, pp. 431-435. [Online]. Available: http://dx.doi.org/10.1109/tsp.2013.6613968

[12] M. Janecek, D. Kubanek, K. Vrba, "Voltage-controlled square/triangular wave generator with current conveyors and switching diodes", International Journal of Advances in Telecommunications Electrotechnics, Signals and Systems, vol. 1, no. 2-3, pp. 1-4, 2012.

[13] H-Ch. Chien, "Voltage-controlled dual slope operation square/triangular wave generator and its application as a dual mode operation pulse width modulator employing differential voltage current conveyors", Microelectronics Journal, vol. 43, no. 12 pp. 962-974, 2012. [Online]. Available: http://dx.doi.org/10.1016/ j.mejo.2012.08.005

[14] J. Kumbun, M. Siripruchyanun, "MO-CTTA-based electronically controlled current-mode square/triangular wave generator", in Proc. of the 1st Int. Conf. on Technical Education (ICTE 2009), Bangkok, 2010, pp. 158-162.

[15] P. Silapan, M. Siripruchyanun, "Fully and electronically controllable current-mode Schmitt triggers employing only single MO-CCCDTA and their applications", Analog Integrated Circuits and Signal Processing, vol. 68, no. 11, pp. 111-128, 2011. [Online]. Available: http://dx.doi.org/10.1007/s10470-010-9593-2

[16] J. Vavra, J. Bajer, D. Biolek, V. Biolkova, "Current-mode quadrature oscillator employing ZC-CDU based all-pass filter", in Proc. IEEE Int. Conf. on Electronics Engineering and Signal Processing (EESP), 2011, Male, pp. 640-644.

[17] J. Vavra, D. Biolek, "OTA-based current differencing unit", in Proc. Int. Conf. on Electronic Devices and Systems (EDS IMPAPS), Brno, 2008, pp. 7-12.

[18] T. Srisakul, P. Silapan, M. Siripruchyanun, "An electronically controlled current-mode triangular/square wave generator employing MO-CCCCTAs", in Proc. 8th Int. Conf. on Electrical Engineering/ Electronics, Computer, Telecommunications, and Information Technology, Khon Kaen, 2011, pp. 82-85. [Online]. Available: http://dx.doi.org/10.1109/ecticon.2011.5947776

[19] A. Sedra, K. C. Smith, "A second generation current conveyor and its applications", IEEE Trans. Circuit Theory, vol. CT-17, no. 2 pp. 132-134, 1970. [Online]. Available: http://dx.doi.org/10.1109/ TCT.1970.1083067

[20] A. Fabre, O. Saaid, F. Wiest, C. Boucheron, "High frequency applications based on a new current controlled conveyor", IEEE Trans. on Circuits and Systems - I, vol. 43, no. 2, pp. 82-91, 1996. [Online]. Available: http://dx.doi.org/10.1109/81.486430

[21] R. Sotner, J. Jerabek, N. Herencsar, "Voltage differencing buffered/ inverted amplifiers and their applications for signal generation", Radioengineering, vol. 22, no. 2, pp. 490-504, 2013.

[22] R. Sotner, J. Jerabek, N. Herencsar, R. Prokop, K. Vrba, J. Petrzela, T. Dostal, "Simply adjustable triangular and square wave genrator employing controlled gain current and differential voltage amplifier", in Proc. 23th Int. Conf. Radioelektronika 2013, Pardubice, 2013, pp. 109-114.

[23] J. Caldwell, "Analog pulse width modulation", TI precision Designs Verified Design (Texas Instruments application recommendations) pp. 1-21, 2013. [Online] Available: http://www.ti.com/lit/ug/ slau508/slau508.pdf

[24] R. Sotner, A. Kartci, J, Jerabek, N. Herencsar, T. Dostal, K. Vrba, "An additional approach to model current followers and amplifiers with electronically controllable parameters from commercially available ICs", Measurement Science Review, vol. 12, no. 6, pp. 255265, 2012. [Online]. Available: http://dx.doi.org/10.2478/v10048012-0035-4

[25] R. Sotner, J. Jerabek, N. Herencsar, T. Dostal, K. Vrba, "Design of Zcopy controlled-gain voltage differencing current conveyor based adjustable functional generator", Microelectronics Journal, vol. 46 , no. 2, pp. 143-152, 2015. [Online]. Available: http://dx.doi.org/10.1016/j.mejo.2014.11.008 